\title{
A construção da figura do louco no Piauí no jornal $O$ Dia: um panorama de 1970 a $2019^{1}$
}

\author{
Camila Fortes Monte FRANKLIN ${ }^{2}$ \\ Juliana Fernandes TEIXEIRA ${ }^{3}$
}

Resumo:

Este trabalho tem como objetivo compreender como se dá a construção da figura do louco no Piauí por meio de matérias do jornal piauiense $O$ Dia que fazem referência à loucura. A pesquisa tem como marco a Reforma Psiquiátrica no Brasil e o recorte temporal é de $1^{\circ}$ de janeiro de 1970 a 31 de dezembro de 2019. Nesse sentido, parte-se de uma contextualização histórica sobre a loucura no mundo para compreender como se caracteriza a figura do louco, como se deu e como se dá essa constituição que atinge diretamente o entendimento social piauiense sobre a pessoa considerada louca e suas variáveis. A pesquisa tem como guia metodológico a formação discursiva desenvolvida por Michel Foucault (2005), a fim de identificar determinadas construções simbólicas existentes nos enunciados analisados.

Palavras-chave: Jornalismo; loucura; formação discursiva; representação; Piauí.

\section{The construction of the figure of the madman in Piauí in the newspaper $O$ Dia: a panorama from 1970 to 2019}

\begin{abstract}
:
This paper aims to understand how the construction of the madman figure in Piauí takes place through journalistic articles of the Piauí newspaper $O$ Dia that make reference to madness. The research has as historical landmark the Psychiatric Reform in Brazil and the time frame is from January 1st, 1970 to December 31st, 2019. In this sense, it starts with a historical contextualization about madness in the world to understand how the figure of the madman is characterized, how it happened and how this constitution takes place, which directly affects the social understanding of Piauí about the person considered insane and its variables. The research has as a methodological guide the discursive formation developed by Michel Foucault (2005) in order to identify certain symbolic constructions existing in the analyzed statements.
\end{abstract}

Keywords: Journalism; madness; discursive formation; representation; Piauí.

\footnotetext{
${ }^{1}$ Este trabalho é um excerto de Dissertação de Mestrado Acadêmico, orientada pela Profa. Dra. Ana Regina Rêgo, a quem registramos um agradecimento especial. 2 Jornalista. Doutoranda em Informação e Comunicação em Saúde na Fundação Oswaldo Cruz (Fiocruz). Bolsista
CAPES. E-mail: camilafortesmonte@gmail.com.

${ }^{3}$ Doutora em Comunicação e Cultura Contemporâneas pela Universidade Federal da Bahia (Salvador/Brasil) e em Ciências da Comunicação pela Universidade da Beira Interior (Covilhã/Portugal), por meio do regime de cotutela entre as duas instituições. Realizou estágio pós-doutoral na Universidade Federal do Piauí, onde, atualmente, é professora do Departamento de Comunicação Social e do Programa de Pós-Graduação em Comunicação Social. Também é professora colaboradora vinculada ao PPGCOM da Universidade Federal do Ceará. É líder do grupo de pesquisa Jornalismo, Inovação e Igualdade. E-mail: teixeira.juliana.rj@gmail.com.
} 


\title{
La construcción de la figura del loco en Piauí en el jornal $O$ Dia: un panorama de 1970 a 2019
}

\begin{abstract}
Resumen:
Este trabajo tiene como objetivo comprender cómo se produce la construcción de la figura del loco en Piauí a través de artículos del diario $O$ Dia de Piauí que hacen referencia a la locura. La investigación tiene como hito la Reforma Psiquiátrica en Brasil y el marco temporal es del 1 de enero de 1970 al 31 de diciembre de 2019. En este sentido, se parte de una contextualización histórica sobre la locura en el mundo para comprender cómo se caracteriza la figura del loco, cómo se sucedió y cómo se da esta constitución, que afecta directamente la comprensión social de la población de Piauí sobre el considerado loco y sus variables. La investigación tiene como guía metodológica la formación discursiva desarrollada por Michel Foucault (2005) para identificar determinadas construcciones simbólicas existentes en los enunciados analizados.
\end{abstract}

Palabras clave: Periodismo; locura; formación discursiva; representación; Piauí.

\section{Introdução}

Durante séculos, o perfil do louco foi sendo construído e reconstruído: ora sujeito irracional, ora super-racional; ora atrelado a patologias, ora isolado de tudo e de todos. Tais construções de potência e não-potência levaram o louco a ser posto em condições isoladas, à margem da sociedade. A loucura foi construída e modificada de acordo com o tempo e o espaço em que estava inserida e, em cada sociedade, havia sua maneira de lidar com os loucos. Com o passar do tempo, esses modos de convivência com a loucura passaram a seguir determinados padrões, ou seja, construiu-se um perfil ideal da loucura.

No Brasil e no Piauí não foi diferente. Ao longo dos anos e da construção das instituições de internação, o louco passa a ser enquadrado em um perfil ideal que comporta determinadas características consideradas legítimas da loucura. Essa construção vem de um histórico de estigmatização implantado na memória coletiva e formatado no decorrer dos anos, que reitera o perfil inconstante do louco, necessitado de interdição e controle familiar, policial e médico.

A presente pesquisa visa, pois, preencher, ainda que parcialmente, uma lacuna em relação à história da loucura no Piauí a partir de uma perspectiva comunicacional. Dito isto, o trabalho parte do seguinte problema: como se dá a construção da figura do louco no Piauí nas matérias do jornal piauiense $O$ Dia? Também buscamos responder: quem são os porta-vozes do louco? Qual a representação do louco no Jornal $O$ Dia? Quais os interesses do Jornal O Dia ao tratar das questões voltadas à saúde mental? E, por fim, em quais contextos sociais e históricos o louco se torna notícia? 
A amostra do trabalho é composta originalmente por trinta notícias jornalísticas do impresso piauiense $O$ Dia no período de 1970 a 2019, selecionadas a partir de um total de 135 matérias encontradas nesse recorte, que fazem referência à loucura ou a um perfil do louco no Piauí. No presente artigo, apresentamos seis notícias, uma de cada categoria, para ilustrar a análise. O critério de seleção das notícias foi desenvolvido com base na formação de um padrão temático a respeito do louco e do que o constituía como sujeito ou pauta jornalística, no qual foram construídas categorias de análise a partir de Michel Foucault (2005; 2008; 1999a; 1999b; 2018), para uma melhor compreensão e organização da análise do trabalho.

\section{Loucura no tempo}

A loucura como produto cultural se configura de maneira relativa se considerarmos os contratos de leitura de mundo. As noções de realidade se alteram de forma individual de modo que os sujeitos que extrapolam essas noções sejam enquadrados como sujeitos desviantes (FOUCAULT, 2008). Dito isto, esta primeira seção do artigo é apresentada a fim de compreender como esses processos de configuração e reconfiguração de um perfil do louco se deram no tempo e na história, através dos seus contextos e transformações diacrônicas.

A constituição histórica da loucura se deu por meio de rupturas e descontinuidades históricas. Sua criação é fruto da invenção e intervenção humana que, por vezes, se modificava, mas também se repetia e se perpetuava. É importante destacar que estamos percorrendo uma construção epistemológica do campo da loucura e do conceito da loucura por um viés social e patológico.

O que hoje se entende por loucura foi construído através do senso comum e de um saber adquirido pelas experiências sociais. As primeiras evidências de um estudo sobre o que se considerava "anormal" datam de 2.500 anos, na Grécia, quando o interesse se baseava na cura de personalidades estranhas que eram consideradas "possessão demoníaca" (STONE, 1999).

Na Idade Média, as pessoas consideradas psicologicamente atingidas eram vistas como uma falha da racionalidade e comumente misturadas aos leprosos, expulsos das cidades e postos em leprosários - instituições criadas pelo poder real no século XIV para controlar e afastar os leprosos das sociedades (FOUCAULT, 2008). Foucault (2008), em A História da Loucura, aponta que o leproso foi uma forte vítima da exclusão social, muitas vezes associado à falta de 
racionalidade. Contudo, na Idade Moderna, os conceitos de loucura reverberaram mediante sinal de extrema racionalidade, tornando, assim, o louco como um sinal de contradição.

No século XVII, com o surgimento das primeiras pesquisas na medicina e das construções de casas de internamento, a loucura se torna produto de pesquisa e entendimento médico. É o que a medicina e a psiquiatria procurarão realizar nos séculos seguintes ao enquadrá-la em diagnósticos sob formas de protocolos de doenças (FOUCAULT, 2008).

\section{A construção da loucura como doença e o poder médico}

Ainda no século XVII, inicia-se um processo de domínio da loucura a partir do saber médico. A psiquiatria surge como instância de controle social dos desatinados que vagavam e importunavam as comunidades e também se propunha a patologizar a loucura, identificando e descrevendo suas características, além de oferecer o que se entendia como um tratamento para os acometidos. A psiquiatria parte de experimentos para procurar uma cura para a loucura, uma vez que esta estará sob vigilância médica.

Assim, à loucura é conferido um status de verdade e seu discurso e suas configurações narrativas são capazes de sustentar determinadas práticas sociais que reforçam o perfil estereotipado do sujeito considerado louco. No século XIX, as estruturas da psiquiatria renunciam a algumas práticas dos séculos anteriores, buscando cada vez mais identificar o perfil e o sujeito louco em meio às demais formas de desatino, a fim de compreender suas origens, curas e formas de diagnóstico (FOUCAULT, 2008).

Um avanço importante com relação ao diagnóstico e ao tratamento das pessoas com transtornos mentais ${ }^{4}$ (até certa época, consideradas “doentes") foi a Reforma Psiquiátrica no Brasil. Esse movimento, que ganhou força no final da década de 1970, criticava o modelo asilar de assistência em saúde mental e a mercantilização da loucura. Outro avanço significativo foi a promulgação da Lei Federal 10.2016/2001 (BRASIL, 2001), que visa garantir os direitos das pessoas com transtornos mentais, fomentando os direitos, o respeito, a igualdade e a dignidade

\footnotetext{
${ }^{4}$ De acordo com a Aliança Global para Inclusão das Pessoas com Deficiência na Mídia e Entretenimento (GADIM), o termo adequado para referir-se a pessoas com algum tipo de transtorno psiquiátrico é "pessoa com transtorno mental" e não "doente mental" ou "portador de doença mental", a fim de desmistificar e romper com estigmas associados a doenças e à incapacidade psíquica.
} 
dessa população. No cenário piauiense, esse histórico da loucura se apresentou de maneira semelhante, mas os avanços médico-psiquiátricos se mostraram bem mais lentos.

\section{A institucionalização e o tratamento das patologias no Piauí}

Carvalho Jr (1980), em História Episcopal do Piauí, aponta que o primeiro registro de demanda por assistência psiquiátrica no Piauí ocorreu em 1761. Os vereadores da Vila da Mocha manifestaram o interesse em criar um Hospício de Religiosos Capuchos, com a finalidade de atender os considerados "desvalidos" na região de Oeiras,

A instituição não chegou a ser construída, mas, em 1849, cria-se o Hospital de Caridade de Oeiras, com o mesmo propósito. Em 1852, a capital do Piauí, até então Oeiras, é transferida para Teresina. Essa mudança deixou a cidade de Oeiras desassistida financeiramente, o que impactou a prestação de serviços públicos de saúde. Em 1907, surge o Asylo dos Alienados em Teresina, sob a direção do médico Areolino de Abreu O Asylo era responsável por atender toda a demanda de assistência psiquiátrica do estado, visto que era um hospital psiquiátrico público, o que em pouco tempo gerou uma superlotação e desassistência aos internos (CARVALHO JR, 1980).

Em 1940, o primeiro médico psiquiatra do Piauí, Clidenor de Freitas Santos, assume a administração do Asylo e ressignifica a assistência psiquiátrica da época com métodos considerados revolucionários e até então não utilizados pela medicina local, como malarioterapia, convulsoterapia e insulinoterapia. Paralelo ao seu trabalho no agora Hospital Areolino de Abreu, Clidenor de Freitas desenvolvia a construção do seu próprio hospital psiquiátrico, o Sanatório Meduna, inaugurado em 21 de abril de 1954, com a proposta de ser o mais inovador para a época, e que veio a atender toda uma demanda do Ceará e do Maranhão. Embora fosse um hospital particular, em pouco tempo seus 517 leitos já estavam ocupados com os considerados "desviantes", ou seja, mendigos, pobres, ociosos, pessoas consideradas “impróprias” para o convívio (FRANKLIN, 2017).

O Sanatório Meduna funcionou durante 56 anos, e, em 2010, apresentou sinais de que passava por dificuldades de manutenção de sua capacidade financeira, administrativa e gerencial, afetando diretamente os internos. Em 2011, o Sanatório Meduna fecha as portas definitivamente e direciona os 200 internos que ainda utilizavam o serviço do Hospital para o 
Hospital Areolino de Abreu e para as Residências Terapêuticas e serviços dos Centros de Atenção Psicossocial (CAPS) (FRANKLIN, 2017).

\section{A construção do perfil do louco no jornal piauiense $O$ Dia}

Fundado pelo professor Raimundo Leão Monteiro, o jornal $O$ Dia teve sua primeira edição publicada em $1^{\circ}$ de fevereiro de 1951 em Teresina, capital do Piauí. Circulando com apenas oito páginas, compostas em sua maioria por assuntos referentes à política local, sendo a maior parte de opinião, concentrava informações sobre os militares da época. O jornal apresentava-se desde a primeira edição como "órgão independente, noticioso e político", o que sugere quais seriam as intenções e os propósitos do jornal, além de definir a linha editorial e seus objetivos de circulação. O jornal não era sustentado por nenhum partido político e isso era um dos fatores para noticiar o que lhes fosse considerado de interesse público.

Logo nos primeiros anos, o jornal passou por constantes revisões no seu projeto gráfico em busca de um modelo simples e de fácil entendimento. É importante compreender que, pelo fato de o jornal possuir apenas duas páginas, a primeira página era destinada às matérias curtas e longas e aos artigos. Com a chegada das cores nas edições, acontece um aumento de duas para quatro páginas, misturando conteúdo editorial e comercial. Em 1953, as características permanecem, mas a quantidade de páginas é reajustada: de quatro passam a ser dez e o uso das cores em algumas delas já começa a definir o que vêm a ser as editorias (FRANKLIN, 2017).

Com o passar dos anos, O Dia se consolida como um dos maiores jornais impressos do estado. Em 2021, com 70 anos, o jornal O Dia leva o slogan "Líder em Credibilidade”. Em sua versão impressa, é composto por dez editorias, além dos cadernos "Em Dia", com informações gerais; "Torquato", com notícias sobre cultura; e caderno de Classificados.

\section{Transformações diacrônicas no jornal $O$ Dia}

Nosso objetivo, como verificação arqueológica, consiste em buscar perceber os múltiplos sentidos discursivos a fim de apontar possíveis relações entre essas significações, apontando as transformações do perfil do louco na história, as mudanças no fazer jornalístico no jornal $O$ Dia e as variações diacrônicas que se dão no tempo e no espaço analisado. 
Considerando o jornalismo como um instrumento de formação de opinião pública, o ethos discursivo é visto como uma noção que recobre os modos de enunciação de um discurso (MAINGUENEAU, 2007), ou seja, os modos de se dizer que, na presente pesquisa, referem-se à maneira de ser e de dizer do jornal no mundo da informação jornalística.

Maingueneau (2007) ainda aponta para o aspecto pragmático do gênero informativo na imprensa, que se funda a partir de uma representação do real e mobiliza formas de evidenciar uma transparência em relação ao real por ela mostrado. Por isso, a observação e análise de periódicos apresenta seu funcionamento e sua visão dos fatos de modo aplicado a partir de uma esfera da produção, circulação e recepção da informação noticiosa.

\section{Amostra}

A amostra do presente trabalho é composta por seis notícias do jornal impresso $O$ Dia no período de 1970 a 2019, selecionadas a partir de um total de 135 notícias encontradas nesse período que fazem referência à loucura ou a um perfil do louco no Piauí. O critério de seleção das notícias foi desenvolvido com base na repetição e na formação de um padrão temático, no qual foram construídas categorias de análise a partir de Foucault $(2008 ; 1999 a ; 1999 b ; 2018)$ para uma melhor compreensão e organização do processo analítico.

A primeira categoria de análise construída é a de um perfil do louco violento ou potencialmente violento. Essa categoria pode ser percebida por meio das características de impulsividade, pressão, violência e raiva a partir do sujeito considerado louco, mas também de medo, temor, receio, desconfiança ou estranhamento da sociedade em relação a ele.

Em contrapartida a esse perfil perigoso ou potencialmente perigoso, a segunda categoria construída é a do louco enquanto vítima, enquanto sujeito que sofre com sua patologia e se torna vítima de si, da sociedade e do sistema em que vive. Essa categoria pode ser identificada tanto nos discursos nos quais o louco é vítima de alguma violência devido a sua patologia, como também naqueles em que o louco se torna digno de pena, ao qual the é imposto o papel de coitado, de não responsável por si, pois já não tem condição de um autocuidado. Para Rauter (2003, p. 40), "os loucos são perigosos, ao mesmo tempo em que enfermos e, por isso mesmo, vítimas de sua condição". 
Em determinado momento, o louco passa a se tornar responsabilidade de outras pessoas ou outras instituições, menos de si mesmo. É o que nos leva à próxima categoria de análise, na qual o louco é visto como responsabilidade da família à qual pertence. Podemos perceber dois caminhos pelos quais a família é responsável pelo louco. O primeiro, baseado na vergonha e na necessidade de esconder da sociedade a figura de um louco na família, e o segundo, em que o louco já não pertence mais às barreiras familiares e causa transtornos na cidade, mas todos sabem à qual família pertence e lhe impõem a obrigatoriedade de um cuidado familiar.

Por outro lado, e em determinado momento, a loucura se torna caso de polícia e esta se apresenta como responsável pelo controle e contenção desses sujeitos. É o que apresentamos na quarta categoria construída: o louco enquanto responsabilidade da polícia. Essa categoria apresenta o estado de vigília em que a polícia se encontra ao tratar de sujeitos considerados loucos em espaços públicos. Ainda no século XVIII, o louco se torna "caso de polícia". Misturado aos leprosos, pobres e pedintes, o louco passa a ser vigiado e, no século XVIII, criamse estruturas próprias para a vigilância desses corpos, como o panóptico (FOUCAULT, 2008), desenvolvido pelo filósofo e jurista inglês Jeremy Bentham.

É importante pontuar que a figura do louco também passou a ser construída a partir da negação e da recusa de determinados padrões impostos à sociedade, como também o perfil de vítima e vulnerabilidade associado ao gênero da pessoa considerada louca. A discussão da relação entre mulher ${ }^{5}$ e loucura surge de registros ainda da Idade Antiga, seguindo até o século XX no Brasil. Essa discussão se encaixa na categoria de Loucura e gênero.

A mulher-louca construída ao longo dos anos aponta um perfil prévio da mulher ideal, responsável por se adequar ao papel de mãe e esposa, dedicada a serviços domésticos e a eterna submissão no casamento. As mulheres que se recusavam a seguir essas normas passavam a ser mal vistas pelas sociedades, tanto por sua falta de adaptação quanto por se tornarem "alheias" a um sistema. Essa categoria pode ser percebida por meio de características de discriminação

\footnotetext{
${ }^{5}$ Compreendemos a categoria "mulher" a partir das características que derivam de um sistema de gênero binário e normativo. Esse sistema compreende que as identidades de gênero são definidas naturalmente em função do sexo biológico (feminino ou masculino) do indivíduo.
} 
apenas pela condição de ser mulher, como também por crimes, abusos, violências físicas, morais e emocionais em relação à figura feminina.

Por fim, a última categoria de análise se configura a partir do eixo de Loucura e políticas públicas com características minimamente sutis de ações voltadas às políticas públicas de assistência ao sujeito considerado louco, bem como um olhar humanizado, voltado às organizações e às instituições de apoio que compreendem a realidade desses sujeitos e buscam soluções em longo prazo.

A repetição de padrões em que o louco se torna notícia no jornal analisado é que nos possibilita a construção dessas categorias, de modo a identificar sob que perspectiva isso aconteceu. A partir disso, partimos para a análise, a começar pela categoria do louco violento ou potencialmente violento.

\section{Louco violento ou potencialmente violento}

A primeira notícia analisada é intitulada "Louco que vivia na jaula fica bom e volta para casa", publicada no dia 25 de janeiro de 1973, na página oito do Caderno 1 do jornal O Dia (Figura 1). A notícia inicia relatando que um homem de nome Anísio Alves Dias, considerado "doente mental", foi preso em uma jaula pela família durante dois anos e que vivia uma vida animalesca, “despido e exposto à população".

Figura 1 - O Dia, 25 de janeiro de 1973, p. 8

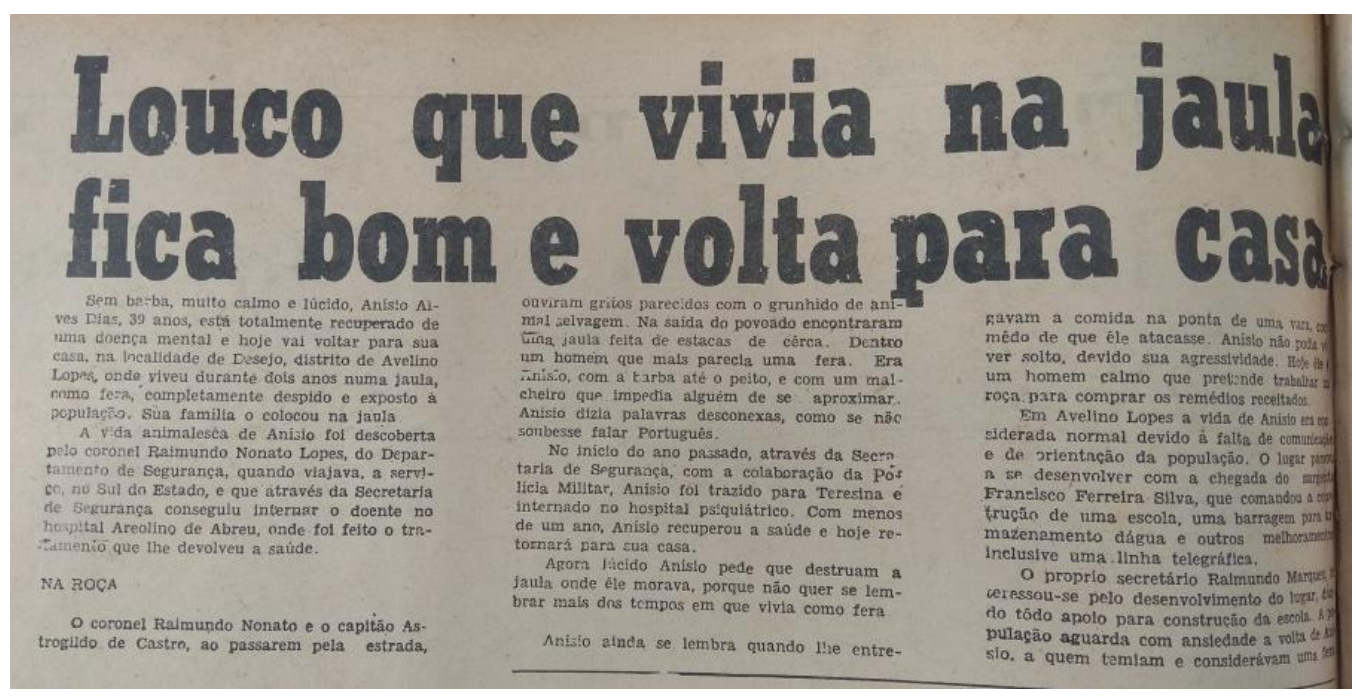

Fonte: Projeto Memória do Jornalismo Piauiense. 
O foco da notícia não consiste no homem ter sido preso em uma jaula durante dois anos, mas sim sobre a sua recuperação após ter sido internado no Hospital Areolino de Abreu. No primeiro parágrafo podemos perceber que as características "sem barba, muito calmo e lúcido" remetem a um perfil ideal de homem, considerando que na década de 1970 essas características eram apresentadas como qualidades.

Ainda no mesmo enunciado, compreendemos que o considerado louco foi posto em uma jaula por apresentar comportamentos contrastantes a esse perfil e que, agora "recuperado", tem o direito de retornar a sua casa, justamente onde sofria os maus tratos. O segundo parágrafo conta que um coronel do Departamento de Segurança descobriu o enjaulamento do homem e conseguiu interná-lo no Hospital Areolino de Abreu, "onde foi realizado um tratamento "que lhe devolveu a saúde" configurando, a partir dessa marca discursiva, a ideia de que antes não a tinha e que a internação no hospital foi capaz de lhe dar a cura.

Comparado a uma "fera", posto em condições precárias de sobrevivência e isolado do resto dos familiares, o julgado como louco perdeu o hábito de se comunicar e passou a viver como um animal. Na década de 1970, havia poucas informações sobre quadros, diagnósticos e tratamentos em relação a transtornos mentais no Brasil e principalmente no Piauí. Em consequência disso, o "louco da família" era sinônimo de vergonha, e o aprisionamento dessas pessoas em suas residências, naturalizado.

\section{O louco enquanto vítima}

A segunda notícia analisada é de título "Louco morre de fome após fugir do Meduna". Publicada em 18 e 19 de julho de 1981, a notícia está localizada na capa e na página nove da edição (Figura 2). O enunciado apresentado na notícia da capa inicia relatando que o considerado "débil mental", de nome Francisco Aguiar de Oliveira, foi encontrado "faminto e agonizando" por seus familiares no centro de Teresina após ter fugido do Sanatório Meduna dias antes. $\mathrm{O}$ homem foi socorrido pela família, mas faleceu antes que recebesse os primeiros socorros. 
Figura 2 - O Dia, 18 e 19 de julho de 1981, p. 9 e Figura 3 (recorte) - O Dia, 18 e 19 de julho de 1981, p. 9
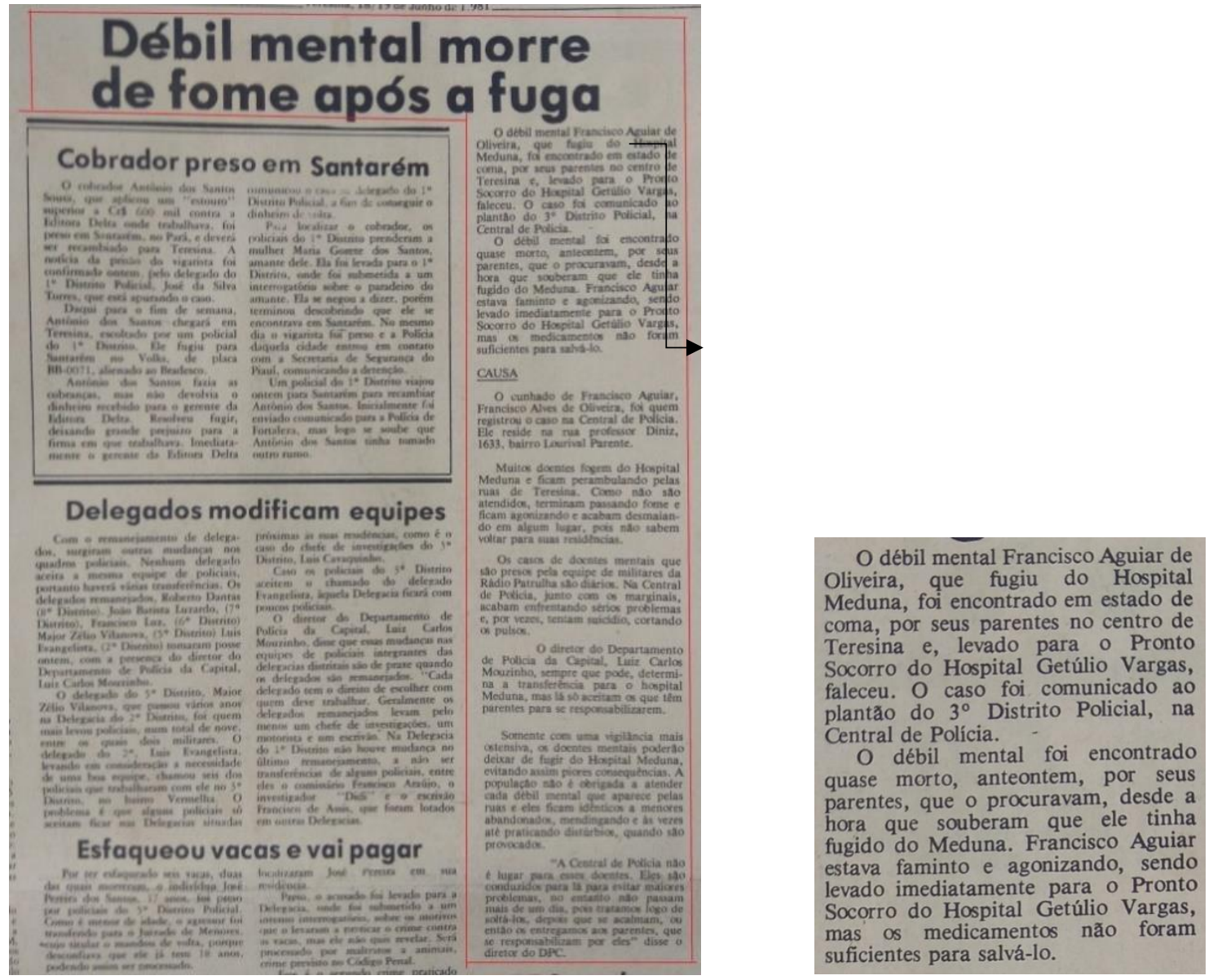

Fonte: Projeto Memória do Jornalismo Piauiense.

A notícia informa que muitos "doentes" fogem do Hospital Meduna e ficam vagando pelas ruas de Teresina, passando fome e sem saber retornar para suas residências. Alguns dos encontrados são presos por uma equipe de militares, mas muitos acabam falecendo de fome nas ruas.

O enunciador segue relatando que os familiares procuraram Francisco Aguiar de Oliveira assim que tiveram conhecimento da fuga e que quando o encontraram, o homem estava "faminto e agonizando". Podemos observar que a responsabilidade pela busca do considerado "débil mental" foi da família, apesar de o homem estar sob os cuidados do hospital psiquiátrico.

No texto, o enunciador pontua que muitos "doentes" fugiam do Sanatório Meduna e ficavam perambulando pelas ruas da cidade. É importante relembrar que na década de 1970 diversas imigrações aconteceram no Piauí. O crescimento populacional fez com que muitas 
pessoas se mantivessem nas ruas. Assim, era comum encontrar andarilhos, pessoas em situação de rua e os considerados "loucos", todos juntos, ocupando os mesmos espaços da cidade, onde uma grande parte dessas pessoas adoeciam, pois não sabiam mais como retornar às suas casas.

O texto segue apontando que o diretor do Departamento de Polícia, "sempre que pode", determina a transferência dos considerados "doentes mentais" da Central de Polícia para o Sanatório Meduna, mas que, no hospital, só aceitam internar quando há um familiar responsável pela internação. Como solução para as fugas do Sanatório Meduna, é afirmado que "somente com uma vigilância mais ostensiva" (DÉBIL...1981, p. 9) os internos deixarão de fugir. É válido destacar que, pelo fato de o Sanatório Meduna localizar-se a poucos metros do Rio Poty, muitos dos internos fugiam nadando, mas acabavam morrendo ao tentar realizar a travessia.

O texto encerra com uma fala do diretor do Departamento de Polícia afirmando que "a Central de Polícia não é lugar para esses doentes" (DÉBIL...1981, p. 9), ou seja, há uma consciência de que essas pessoas não devem ficar nessas instituições. Além disso, muitos são encaminhados para as delegacias e centrais, a fim de evitar a circulação no convívio da sociedade, ou seja, o objetivo maior é a retirada dessas pessoas das ruas e seu isolamento.

O discurso e a linguagem utilizada apresentam as condições de produção de sentido em relação ao sujeito louco, reforçando as medidas de exclusão, aprisionamento e vergonha, contendo o ideário de que "cada família é responsável pelo seu louco", o que nos leva à próxima categoria de análise.

\section{Louco enquanto responsabilidade familiar}

A notícia analisada tem por título "Criança vive amarrada há 12 anos em União", publicada em 28 de dezembro de 1974, na página 12, editoria de Polícia, do $1^{\circ}$ Caderno da edição. O texto inicia afirmando que o Serviço Social do Estado mandou hospitalizar, para um tratamento, uma criança de 15 anos “cujo estado psíquico é tão delicado que é obrigado a viver amarrada como um pequeno animal, tal o seu estado de violência”. 
Figura 4 - O Dia, 28 de dezembro de 1974, p. 12

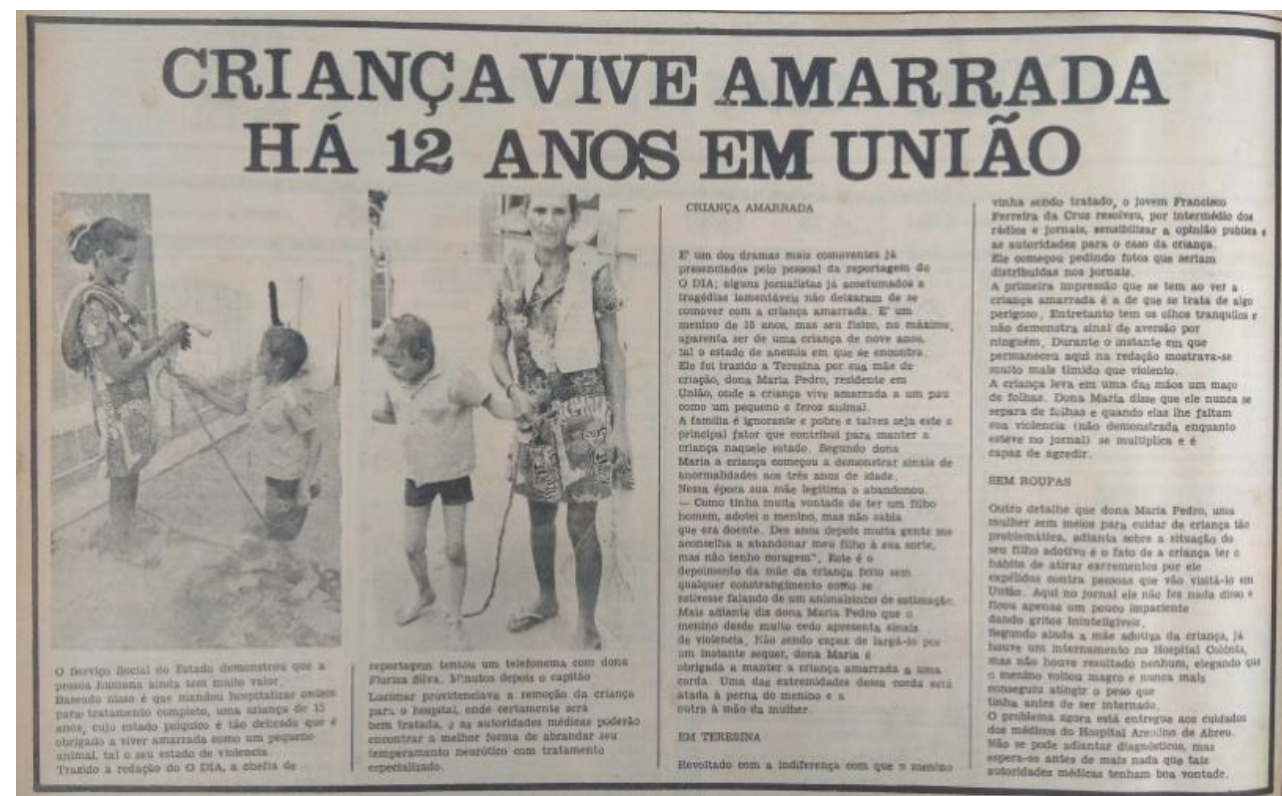

Fonte: Projeto Memória do Jornalismo Piauiense.

Criado por uma mãe adotiva, o menino vivia há doze anos amarrado a uma árvore por ser considerado por ela como perigoso a si e às outras pessoas. O enunciador afirma que a criança "vive amarrada a um pau como um pequeno e feroz animal" (CRIANÇA... 1974, p. 12), o que nos faz refletir sobre a comparação entre um menino e um animal, colocando o considerado "doente mental" em uma posição animalesca, associada às características de imprevisibilidade e periculosidade.

O trecho "Como tinha muita vontade de ter um filho homem, adotei o menino, mas não sabia que era doente. Dez anos depois muita gente me aconselha a abandonar meu filho à sua sorte, mas não tenho coragem" (CRIANÇA... 1974, p. 12) demonstra que, se a mãe adotiva tivesse conhecimento da condição psíquica do menino, não o teria adotado. O enunciador segue fazendo uma comparação do menino com um "animalzinho de estimação", colocando a criança em um estado animalesco, além de reforçar a relação de dependência do filho quanto à mãe adotiva e a responsabilidade familiar em relação ao considerado "louco".

No texto se apresentam detalhes do comportamento do menino quando se encontrava em estado agressivo. Podemos supor que muito desse comportamento pode ter se dado justamente pela condição de estar amarrado há doze anos. Além disso, a marca discursiva “dona Maria Pedro, uma mulher sem meios para cuidar de criança tão problemática" (CRIANÇA..., 
1974, p. 12) revela que nem mesmo a mãe adotiva da criança teria condições de cuidar do menino e que o melhor que poderia acontecer a ele era sua internação.

Essa responsabilidade de cura do menino em relação à sua agressividade é posta como esperança não mais na mãe adotiva, mas na instituição psiquiátrica. Nessa notícia podemos perceber a responsabilidade familiar concentrada na figura dessa mãe adotiva que, sozinha, a partir dos métodos que considerou mais adequados e da maneira que conseguiu, cuidou e criou do menino que adotou.

Assim como o louco se torna responsabilidade familiar, em uma linha tênue, esse mesmo louco se torna caso de polícia, visto a necessidade de contenção desses corpos.

\section{Louco enquanto responsabilidade policial}

Publicada em 13 de abril de 1973, na página oito do $1^{\circ}$ Caderno da edição, a notícia analisada tem por título "Segurança nervosa com tantos loucos".

Figura 5 - $O$ Dia, 13 de abril de 1973, p. 8

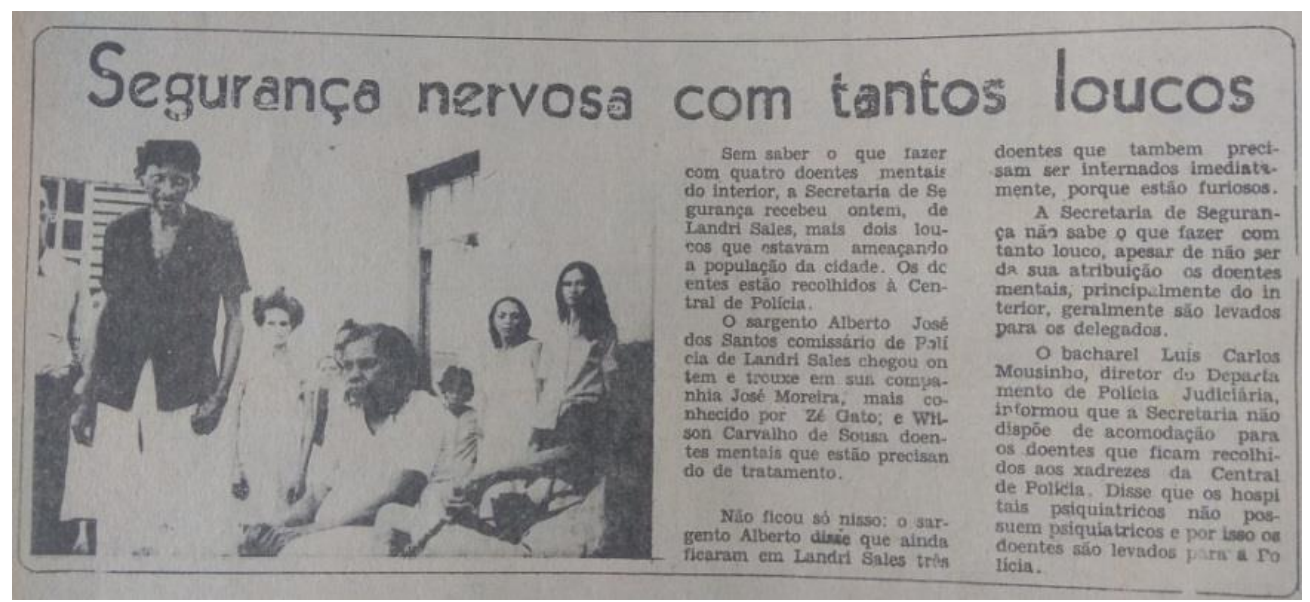

Fonte: Projeto Memória do Jornalismo Piauiense.

Notamos, a partir do trecho "Segurança nervosa com tantos loucos", que os órgãos de segurança pública, considerados os responsáveis por manter a ordem e a segurança da população, agora se apresentam desestabilizados, sem muitas opções sobre como proceder com a superlotação de pessoas com transtornos mentais nas cadeias e centrais de polícia.

O texto inicia afirmando que a Secretaria de Segurança recebeu de Landri Sales, cidade do interior do Piauí, "mais dois loucos que estavam ameaçando a população da cidade" 
(SEGURANÇA..., 1973, p. 8). A notícia não identifica quem de fato enviou essas pessoas à Secretaria de Segurança, mas podemos notar que a intenção era a retirada dessas pessoas dos espaços públicos e o aprisionamento desses corpos.

Não sabemos se a retirada dessas pessoas foi uma decisão familiar, médica, jurídica, social ou policial. O fato é que havia um grande número de imigrantes com transtornos mentais vindos do interior do estado para serem tratados da "doença da loucura". O discurso utilizado pelo sargento é o de que essas pessoas estavam “furiosas”. Novamente, é reforçado o estereótipo de agressividade relacionado ao considerado louco.

O enunciador do texto segue pontuando que a Secretaria de Segurança "não sabe o que fazer com tanto louco" e que, apesar de não ser sua responsabilidade, um grande número de pessoas consideradas "doentes mentais" (SEGURANÇA..., 1973, p. 8) é levado para as delegacias e o objetivo é claro: a contenção e o controle desses corpos vistos como agressivos.

No último parágrafo da notícia, o enunciado traz a fala do diretor do Departamento de Polícia Judiciária informando que a Secretaria não dispõe de acomodação para os considerados "doentes" que ficam "recolhidos" nas Centrais de Polícia. A marca discursiva "recolhidos" é utilizada aqui como forma de amenizar um termo de aprisionamento ou encarceramento, fazendo acreditar que é para o bem da sociedade que essas pessoas estão presas nas Centrais.

Os hospitais psiquiátricos não tinham mais leitos disponíveis e essa era uma informação facilmente compartilhada entre as instituições de segurança pública. É válido destacar que essas pessoas eram levadas para a capital sem nenhum tipo de assistência, ou seja, transferidas sem nenhum acompanhante, o que nos faz questionar como essas pessoas eram internadas se o procedimento de internação somente era aberto se houvesse um responsável familiar para se comprometer ao acompanhamento psiquiátrico. Acreditamos que o poder policial existente seria responsável por essas autorizações, considerando o bem-estar social como prioridade pública.

Uma outra característica na qual a responsabilidade policial interfere diretamente no corpo do sujeito considerado louco é quando esse corpo passa feminilidade. 


\section{Loucura e gênero}

A notícia com o título "A doce liberdade da menina louca" foi publicada em 23 de março de 1979, na página oito do Caderno 1 da edição (Figura 6).

Figura 6 - O Dia, 23 de março de 1979, p. 8

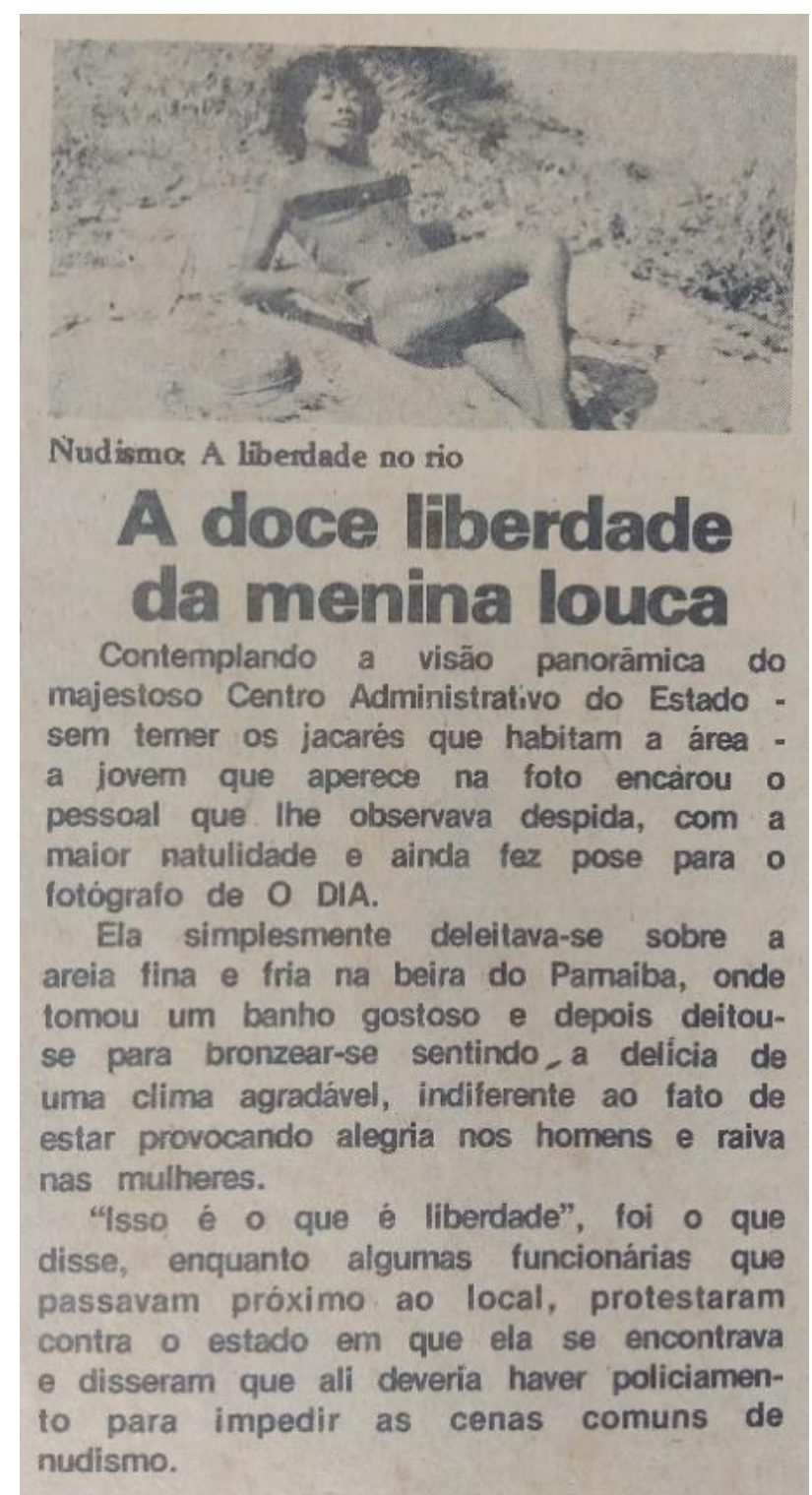

Fonte: Projeto Memória do Jornalismo Piauiense.

A imagem que ilustra a notícia tem como subtítulo "Nudismo: A liberdade no rio". Podemos identificar a partir desse enunciado que seu estado de nudez é apresentado como uma 
liberdade a ser desfrutada e carrega em si uma infantilização da jovem como se ela não tivesse a noção do que a sua nudez pudesse representar, considerando o contexto narrativo.

O seu corpo não é respeitado e é válido refletir se esse desrespeito acontece pela nudez em que a mulher se encontrava ou se é por ser considerada louca, dando margem para que seja considerada assim justamente pelo estado de naturalização da própria nudez. No primeiro parágrafo da notícia, a marca discursiva "encarou o pessoal que lhe observava despida, com a maior naturalidade" (A DOCE..., 1979, p. 8) reflete um perfil naturalizado dessa mulher considerada louca, de quem não teme e não se importa com determinadas normas sociais impostas, caracterizado como "típico de um louco", por meio das características de descuido e despreocupação.

Considerada como responsável pelo desconforto da população, a jovem foi entrevistada - o que significa que lhe deram o direito de voz. No entanto, acreditamos que essa fala foi colocada de maneira tendenciosa, até mesmo ridicularizada, a fim de expor a jovem.

O trecho "disseram que ali deveria haver policiamento para impedir as cenas comuns de nudismo" (A DOCE..., 1979, p. 8) reflete, por uma polifonia, que a melhor solução era a retirada forçada dessas pessoas pela segurança policial e que as cenas comuns de nudismo também retratavam um incômodo e a necessidade de higienização social, característica dada constantemente ao sujeito considerado louco.

Essa mulher-louca apresentada na notícia acima poderia ter algum tipo de transtorno mental comprovado, mas o que percebemos é que esse diagnóstico foi apresentado de maneira prévia, por ela ter tomado banho de rio sem roupa, sem se preocupar com as pessoas à sua volta. É importante considerar o contexto histórico em que a notícia foi publicada, pois essa mulher percebida como louca era vista como uma afronta ao perfil ideal de mulher construído na década de 1970, em particular na capital Teresina, onde a sociedade era bastante conservadora e o corpo da mulher, visto como um ser submisso e fetiche sexual.

Um perfil infantilizado foi construído sobre essa mulher-louca, de modo que ela não responda por si, mas que seja silenciada e anulada em sua existência. Desse modo, a infantilização deslegitima sua fala, seu corpo e sua liberdade, esta última tão desejada e esperada pelos sujeitos considerados desviantes, que veio a acontecer somente anos depois e de maneira sutil e gradual. 


\section{Loucura e políticas públicas}

A última notícia analisada tem por título "Nova filosofia humaniza saúde", e foi publicada em $1^{\circ}$ de novembro de 1994, na página 9, na capa do caderno de Cidades (Figura 7).

Figura 7 - O Dia, 1 de novembro de 1994, p. 9

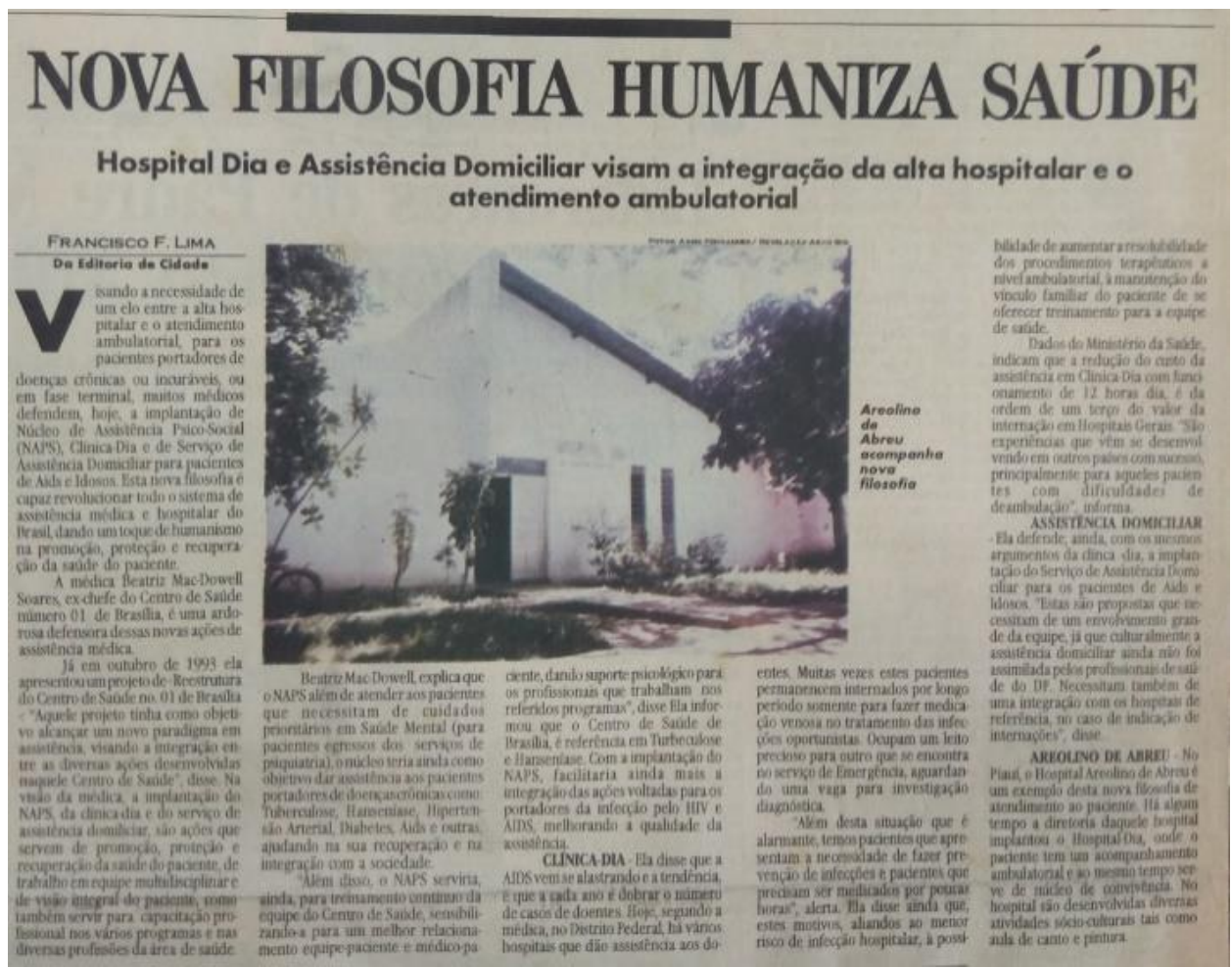

Fonte: Projeto Memória do Jornalismo Piauiense.

O texto inicia pontuando sobre a necessidade de uma integração entre a alta hospitalar e o atendimento ambulatorial para as pessoas com transtornos mentais usuárias do sistema de saúde ou "para os pacientes portadores de doenças crônicas ou incuráveis ou em fase terminal" (NOVA..., 1994, p. 9). Observamos que essas instituições oferecem tratamento e atendimento não somente para pessoas com transtornos mentais, mas também pessoas com doenças crônicas como tuberculose, diabetes, HIV-AIDS, entre outros males que necessitariam de uma maior assistência médica e hospitalar.

Acontecia uma ascensão na medicina no Brasil em benefício da saúde coletiva e o Piauí buscava acompanhar essa evolução, afinal, era considerado um polo de saúde desde a década de 1970 e muitos investimentos eram realizados em prol desse avanço do Estado em relação ao 
país. O texto segue pontuando sobre a relevância de um atendimento especializado para pessoas com HIV-AIDS, considerando o crescente número de diagnósticos que surgiam no Brasil e no Piauí na década de 1990.

O texto encerra pontuando sobre os avanços realizados dentro do Hospital Areolino de Abreu, como é o caso da implantação do Hospital-Dia e das atividades terapêuticas executadas dentro da instituição psiquiátrica. Nessa notícia, podemos identificar uma solidificação do atendimento e da assistência psiquiátrica no Hospital Areolino de Abreu na década de 1990. Contudo, não podemos esquecer que, ainda assim, era um hospital psiquiátrico de modelo manicomial em sua estrutura, que se utilizou de métodos agressivos e invasivos por mais de cinquenta anos e que passou por um processo de implementação de políticas públicas há menos de trinta anos.

\section{Considerações finais}

Mediante o exposto, percebemos que a construção da figura do louco no Piauí no jornal O Dia aconteceu de modo a reproduzir os estereótipos já existentes referentes a perigo, imprevisibilidade e incapacidade, necessidade de interdição e controle familiar, médico, institucional ou policial, ou, por vezes, de todos ao mesmo tempo. Identificamos que o louco é visto também como um problema institucional, relacionado mais aos órgãos de segurança pública do que aos de saúde pública, em vista da necessidade de isolamento dos considerados loucos dos espaços públicos.

Observamos que o jornal $O$ Dia trata a temática da loucura de modo superficial, não atendendo às necessidades dos profissionais de saúde nem respeitando os usuários do sistema de saúde mental. Não havia preocupação com a exposição dessas pessoas, e elas não eram ouvidas, necessitando de um porta-voz para representá-las. Acreditamos ainda que a preocupação do jornal $O$ Dia tenha se alterado ao longo do tempo ao tratar das questões voltadas à saúde mental. De início, as construções narrativas giravam em torno da veiculação imediata do fato, não se aprofundando nas proposições de assistência nem nas questões de sociabilidade.

Notamos, contudo, com o passar do tempo, uma preocupação jornalística em dar voz aos sujeitos envolvidos e em noticiar informações com o objetivo de desconstruir determinados preconceitos que eram constantemente associados à pessoa com transtorno mental. $\mathrm{O}$ fazer 
jornalístico se altera e se adapta de acordo com as necessidades das sociedades. Apesar disso, compreendemos que essa preocupação jornalística parte também de um interesse mercadológico, com o objetivo de se consolidar como jornal imparcial, confiável e legítimo para a sociedade e para os investidores.

Constatamos também que o louco só se torna notícia em $O$ Dia quando acontece algum fato marcante que quebre a rotina da sociedade, em sua maioria relacionados a tragédias, crimes, superlotação, ou em casos em que a assistência psiquiátrica necessita de atenção pública e governamental. Dito isto, como resultado direto da presente pesquisa, observamos a existência e a transformação de construções narrativas no que se refere ao louco que, em sua maioria, reforçam uma variedade de perfis.

Entretanto, percebemos que essa variedade de perfis faz parte de um único perfil multifacetado, complexo, que se modificou ao longo do tempo e deixou cicatrizes e marcas historiográficas. Acreditamos que, por essas questões, dentro do processo analítico, uma notícia poderia ser enquadrada em mais de uma categoria, considerando a fluidez da construção da figura do louco. Assim, o presente trabalho almeja preencher, ainda que parcialmente, uma lacuna nas pesquisas sobre a loucura no Piauí, assim como perceber novas possibilidades de formação discursiva e de construção noticiosa no que diz respeito às pessoas com transtornos mentais.

\section{Referências}

A DOCE liberdade da menina louca. O Dia, Teresina, 23 mar. 1979. Caderno 1, p. 8.

BRASIL, Gadim. Cópia Manual da Mídia Digital. Aliança Global para Inclusão das Pessoas com Deficiência na Mídia e Entretenimento. Disponível em: https://www.gadimbrasil.org/copia-manual-da-midia-legal. Acesso em: 18 set. 2020.

BRASIL. Lei 10.216, de 6 de abril de 2001. Dispõe sobre a proteção e os direitos das pessoas portadoras de transtornos mentais e redireciona o modelo assistencial em saúde mental. Diário Oficial da União, Brasília, DF, 9 abr. 2001. Seção 1. Disponível em: http://www.planalto.gov.br/ccivil_03/leis/leis_2001/110216.htm. Acesso em: 20 set. 2020.

CARVALHO JÚNIOR, Dagoberto. História episcopal do Piauí. Teresina: COMEPI, 1980. 
CRIANÇA vive amarrada há 12 anos em União. O Dia, 28 dez. 1974. Caderno 1, editoria Polícia, p. 12.

DÉBIL mental morre de fome após a fuga. O Dia, Teresina, p. 9, 18 e 19 jul. 1981.

FOUCAULT, Michel. Arqueologia do saber. Rio de Janeiro: Forense Universitária, 2005.

FOUCAULT, Michel. História da loucura na Idade Clássica. São Paulo: Perspectiva, 2008.

FOUCAULT, Michel. História da Sexualidade 1: a vontade de saber. Rio de Janeiro: Edições Graal, 1999a.

FOUCAULT, Michel. Microfísica do poder. Rio de Janeiro/São Paulo: Paz e Terra, 2018.

FOUCAULT, Michel. Vigiar e punir: nascimento da prisão. Petrópolis: Vozes, 1999b.

FRANKLIN, Camila Fortes Monte. Stultifera Navis: A invisibilidade do louco nas matérias dos jornais O Dia e O Piauí no mês de inauguração do Sanatório Meduna. 2017. Trabalho de Conclusão de Curso (Bacharelado em Comunicação Social com habilitação em Jornalismo) Universidade Federal do Piauí, Teresina, 2017.

LOUCO morre de fome após fugir do Meduna. O Dia, Teresina, p. 1 e 9, 18 e 19 jul. 1981.

LOUCO que vivia na jaula fica bom e volta para casa. O Dia, Teresina, 25 jan. 1973. Caderno 1, p. 8.

MAINGUENEAU, Dominique. Gênese dos discursos. Curitiba: Criar, 2007.

MENINO vive 12 anos amarrado a uma árvore. O Dia, Teresina, 28 dez. 1974. Caderno 1, editoria Polícia, p. 12.

NOVA filosofia humaniza saúde. O Dia, Teresina, 1 nov. 1994. Caderno Cidades, p. 9.

RAUTER, C. Criminologia e subjetividade no Brasil. Rio de Janeiro: Revan, 2003.

SEGURANÇA nervosa com tantos loucos. O Dia, Teresina, 13 abr. 1973. Caderno 1, p. 8.

STONE, Michael. H. A cura da mente: a história da psiquiatria da Antiguidade até o presente. Porto Alegre: Artmed, 1999.

Submetido em: 04.04.2020.

Aprovado em: 19.06.2021. 